\title{
ARTIFICIAL INTELLIGENCE IN THE MANUFACTURING INDUSTRY
}

\author{
Matthew N. O. Sadiku ${ }^{1}$, Sarhan M. Musa ${ }^{1}$ and Osama M. Musa ${ }^{2}$ \\ ${ }^{1}$ Roy G. Perry College of Engineering \\ Prairie View A\&M University \\ Prairie View, TX 77446 \\ ${ }^{2}$ Ashland Inc. \\ Bridgewater, NJ 08807, USA
}

\begin{abstract}
Artificial intelligence is one of the many technologies currently impacting manufacturing. Over the years, the manufacturing industry has exploited the use of artificial intelligence, which is the imitation of human-like intelligence (aspects of recognition, perception, decision making, etc.) exhibited by machines. This paper briefly addresses the uses of artificial intelligence in the manufacturing industry.
\end{abstract}

Key Words: Artificial intelligence, Manufacturing.

\section{INTRODUCTION}

Artificial intelligence (AI) is the cognitive science that deals with intelligent machines which can perform tasks heretofore only performed by human beings. It is mainly concerned with applying computers to tasks that require knowledge, perception, reasoning, understanding, and interpretive cognitive abilities. Artificial intelligence is potentially the algorithmic study of processes in every field of study [1]. The main objective of artificial intelligence is to teach the machines to respond like humans do to flows of data (instrument readings, voice commands, visual perception, and so on).

Artificial intelligence is a science with research activities in the areas of image processing (e.g. facial recognition systems), natural language processing (e.g. automated voice response customer service systems), robotics, machine learning, etc. It began as an active field of research within computer science in about 1955. Today, artificial intelligence in smart machines handles many traditional repetitive tasks.

Artificial intelligence has many applications in today's society. Although artificial intelligence is a branch of computer science, there is hardly any field which is unaffected by this technology. Common areas of applications include agriculture, business, law enforcement, oil and gas, banking and finance, education, transportation, healthcare, automobiles, entertainment, manufacturing, speech and text recognition, facial analysis, and telecommunications. Over the years, the field of artificial intelligence has produced a number of tools for manufacturing. Today industrial leaders such as Google, Microsoft, and IBM have invested heavily on artificial intelligence. 
International Journal of Advances in Scientific Research and Engineering (ijasre), Vol 5 (6), June-2019

\section{MANUFACTURING}

Manufacturing refers to the entire product life cycle: product design, production planning, production, distribution, and field service and reclamation [2]. The manufacturing industry has always been receptive to adopting new technologies such as drones, industrial robots, virtual reality, Internet of things (IoT) and artificial intelligence. These days, humans and robots collaborate to produce breakthrough technologies.

Manufacturing is regarded as a prime generator of wealth and critical in establishing a sound basis for economic growth. The leading manufacturing industries in US include steel, automobiles, chemicals, food processing, consumer goods, aerospace, and mining. Globalization has radically changed the manufacturing process in recent years.

An area of manufacturing where artificial intelligence has been applied with great success is aircraft assembly [6] and design [7]. Manufacturing efficiency and maintaining product quality remain top priorities in areas such as the integrated circuit (IC) industry, where process and equipment reliability directly influence cost, throughput, and production yield [3]. Recent widespread adoption and developments that have enabled artificial intelligence to cross into the mainstream include cloud computing, big data, machine learning, and the Internet of things.

\section{BENEFITS AND CHALLENGES}

Artificial Intelligence can enhance and extend the capabilities of humans. With the help of artificial intelligence, manufacturing will lead to higher productivity and increased efficiency. Artificial intelligence is poised to impact the supply chain. Manufacturing is a high-cost venture for most businesses and it requires considerable capital investment. There is the common fear of human jobs being lost to artificial intelligence. This will require retraining or redeploying human workers to new careers. With automation, it is easy to believe that machines outperform human workers at every turn. It is possible for artificial intelligence to develop a "will" of its own that may conflict with ours. Industrial robots perform what they were programmed to do, but they currently cannot readily make complex decisions that humans routinely tackle. That is likely to change in the future and we can already see that direction impacting marketing based on vague preferences. In addition, the increasing use of connected technologies will certainly make manufacturing systems more vulnerable to cyber-attacks [4].

\section{CONCLUSION}

Artificial intelligence deals with computational systems that imitate the intelligent behavior of expertise. Without doubt artificial intelligence holds the key to future growth and success in manufacturing. There is an excellent future for use of artificial intelligence in manufacturing due to the potentially high value added when applied successfully [5]. The future will witness a deep fusion of new artificial intelligence technologies with Internet technologies.

\section{REFERENCES}

[1] M. N. O. Sadiku, "Artificial intelligence", IEEE Potentials, May 1989, pp. 35-39.

[2] M. S. Fox," Industrial applications of artificial intelligence," Robotics, vol. 2, 1986, pp. 301-311.

[3] "Artificial intelligence in semiconductor manufacturing," in J. Webster (ed.), Wiley Encyclopedia of Electrical and Electronics Engineering, John Wiley \& Sons,2007. 
International Journal of Advances in Scientific Research and Engineering (ijasre), Vol 5 (6), June-2019

[4] J. Lee et al., "Industrial artificial intelligence for Industry 4.0-based manufacturing systems," Manufacturing Letters, 2018.

[5] T. M. Knasel, "Artificial intelligence in manufacturing: Forecasts for the use of artificial intelligence in the USA," Robotics, vol. 2, 1986, pp. 357-362.

[6] H Rao; "AI Driven Transformation"; Boeing Innovation Quartley, February 2017 (www.boeing.com/ features/innovation-quarterly/feb2017/feature-leadership-rao.page)

[7] M McKnight; "Generative Design: What it is? How is it Being Used? Why it's a Game Changer" International Conference on Design and Technology, KEG, p 176-181.

\section{AUTHORS}

Matthew N.O. Sadiku is a professor in the Department of Electrical and Computer Engineering at Prairie View A\&M University, Prairie View, Texas. He is the author of several books and papers. His areas of research interest include computational electromagnetics and computer networks. He is a fellow of IEEE.

Sarhan M. Musa is a professor in the Department of Engineering Technology at Prairie View A\&M University, Texas. He has been the director of Prairie View Networking Academy, Texas, since 2004. He is an LTD Sprint and Boeing Welliver Fellow.

Osama M. Musa is currently Senior Vice President and Chief Technology Officer for Ashland Inc. Dr. Musa also serves as a member of the Advisory Board at Manhattan College's Department of Electrical and Computer Engineering as well as a member of the Board of Trustees at Chemists' Club of NYC. Additionally, he sits on the Advisory Board of the International Journal of Humanitarian Technology (IJHT). 